\title{
Changes in walkability in three urban neighborhoods of the city of Rome: a comparison 2009-2019 Letizia Appolloni
}

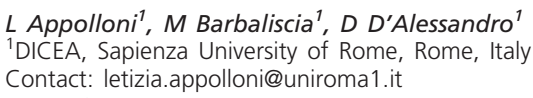

An audit, through T-WSI, is carried out for each street of a neighborhood. T-WSI audit evaluates 12 indicators subdivided into 4 categories: practicability, safety, urbanity, pleasurableness. The weighted analysis of these indicators gives an overall score of the actual usability of the neighborhood. In this study, 2 different trained surveyors, evaluated T-WSI in three neighborhoods of Rome (San Saba, Sacco Pastore and Tufello-Val Melaina), which differ in socio-economic conditions. Average scores have been compared using t-student.

Results:

A considerable improvement was observed in the Sacco Pastore neighborhood final weighted scores (T-WSI scores: from 53.6 in 2009 to 68.3 in 2019 , with an increase of $14.7 \%$ $(\mathrm{p}<0.005)$. All categories improved, although Safety (T-WSI scores: from 35.0 to 59.3 ; increase of $24.3 \%-\mathrm{p}<0.005)$ and Pleasurableness (T-WSI scores: from 48.5 to 61.4 ; increase of $12.9 \%-\mathrm{p}<0.005)$ show the greatest improvements. It is mainly due to redevelopment works carried out in the neighborhood in the last 10 years, mainly aimed to increase citizen's perceived safety (e.g. signs, crossing protection devices, traffic lights, greenery management) and to remove architectural barriers.

\section{Conclusions:}

The results show T-WSI is a useful tool in order to measure the effectiveness of the interventions already realized at local level, but it could also contribute to making decisions to develop regeneration projects for degraded areas of the cities. 
Key messages:

- Physical Activity must become a priority and part of a daily routine.

- Healthy cities, healthy people. 